\title{
Phenotypic, Biochemical and Molecular Diversity of Phoma lingam Fungal Isolates Collected from Saskatchewan, Canada
}

\author{
Rafiq Ahad ${ }^{1}$, Ginette Séguin-Swartz ${ }^{2}$, Richard K. Gugel ${ }^{2}$, Birger Koopmann ${ }^{3}$ \\ ${ }^{1}$ Centre for Biodiversity Genomics, University of Guelph, Ontario, Canada, N1G 2W1 \\ ${ }^{2}$ Agriculture and Agri-Food Canada, 107 Science Place, Saskatoon, Saskatchewan S7N 0X2, Canada \\ ${ }^{3}$ Division of Plant Pathology and Crop Protection, University of Göttingen, Grisebachstrasse 6, 37077 Göttingen, Germany
}

\begin{abstract}
The population of Phoma lingam associated with blackleg disease of canola (Brassica napus) is highly polymorphic, and infect various Brassicaceae species, including Thlaspi arvense (stinkweed). In order to determine the population composition and pathogenicity of $P$. lingam infecting $T$. arvense, 18 isolates recovered from $T$. arvense (designated 'Thl' isolates) from different crop fields of Saskatchewan were compared with an aggressive (IBCN 2) and eleven less/non-aggressive reference strains. No common morphological, biochemical and pathogenic characteristics were found between 'Thl' isolates and IBCN 2 strain. DNA fingerprinting and phylogenetic analysis of ITS-rRNA gene sequences revealed that the 'Thl' $P$. lingam population of Saskatchewan is highly heterogeneous and comprised of at least eight genotypes. Over 50 percentage of 'Thl' isolates clustered with different less/non aggressive reference strains belonging to L. biglobosa. Interestingly, a group of' Thl' isolates clustered with an aggressive reference strain, IBCN 2. Therefore, regular monitoring is required to determine if the 'Thl' $P$. lingam population of western Canadian provinces is migrating from non-aggressive toward aggressive state.
\end{abstract}

Keywords: Blackleg disease, genetic diversity, ITS-rRNA sequence, oilseed rape, Phoma lingam

\section{Introduction}

Phoma lingam is an economically important pathogen of oilseed rape/canola (Brassica napus L.) and other brassica plants (e.g., B. oleracea, B. rapa) across the world $[1,2]$. Populations of the fungus are highly polymorphic and thought to consist of a species complex [3, 4]. Initially, $P$. lingam isolates that cause blackleg or stem canker on Brassica napus or B. oleracea and produce the hostnonspecific toxins 'sirodesmins' were designated as ' $A$ ' group or aggressive or $\operatorname{Tox}^{+}[5,6]$. In contrast, isolates that cause no or little disease on those hosts and do not produce sirodesmins were termed ' $\mathrm{NA}$ ', non-aggressive or Tox'. Subsequent molecular, biochemical and pathogenicity studies showed that isolates of the ' $A$ ' and 'NA' groups belong to two teleomorphic species of $P$. lingam, namely Leptosphaeria maculans and L. biglobosa, respectively [7, 8]. The two species occur in similar ecological niches but produce distinctive infection symptoms. L. maculans causes damage on lower stems while L. biglobosa infects upper stems of B. napus [6, 9]. Isolates belonging to two groups/species appeared to be comprised of multiple subgroups that often correspond to host plants and geographical origins $[10,11]$. ' $A$ ' group comprised of at least two sub-groups, namely L. maculans 'brassicae' (isolates collected from B. napus) and L. maculans 'lepidii' (isolates from Lepidium sp.) [11]. In contrast, the NA group appeared to be highly heterogeneous [12] and could be divided into different sub-groups distinguished by their host plant and country origins. 'NA' isolates originating from oilseed rape and cole crops are designated 'brassicae' (NA1, Europe), 'canadensis' (NA2, Canada), NA3 (USA), and 'australiensis' (NA-Aus, Australia) and 'occiaustralensis' (Australia). The isolates from cruciferous weeds have been designated as 'erysimii' (Erysimum sp.), 'thlaspii' (Thlaspi arvense), and 'sysimbrii' (Sysimbrium sp.) [8, 11, 13]. Importantly, shifts of non pathogenic populations of $P$. lingam to a highly pathogenic state have been observed in Canada and on other continents $[13,14,15]$.

This research aimed at elucidating the population structure and pathogenic behaviour of P. lingam isolates collected from $T$. arvense from canola growing areas of Saskatchewan and other western Canadian provinces. To achieve the objectives the morphological and biochemical characteristics, aggressiveness on B. napus plants and genetic variability of the 'Thl' isolates were studied by comparing to a number of $P$. lingam reference strains exists in different continents. The work is expected to determine if $T$. arvense serves as an alternate host of $P$. lingam potentially harmful to canola.

\section{Materials and Methods}

\section{Fungal isolates}

Eighteen isolates of P. lingam isolated from T. arvense, designated 'Thl' isolates, were compared with strains from the International Blackleg of Crucifers Network (IBCN). The IBCN collection representative of $13 P$. lingam isolates belonging to the A- and NA groups, and $L$. maculans and $L$. biglobosa (Table 1). The isolates Thl-10 to 13 were isolated from seed of $T$. arvense collected in a canola field infected with blackleg on the Agriculture and Agri-Food Canada (AAFC)-Research Farm near Melfort, Saskatchewan, Canada; isolates Thl-14 to 28 were isolated from seed of plants collected near Eastend in south-western Saskatchewan, which is outside of the traditional canola production zone. 
Table 1. Isolates of Phoma lingam used in the study

(a) Isolates collected from Thlaspi arvense

\begin{tabular}{|llll|}
\hline Isolates & Location & Isolated from & Year collected \\
\hline Thl-10 to 13 & AAFC $^{*}$-Melfort Research Farm, Saskatoon, SK & Canola field & 2000 \\
Thl-14 to 23 & Site 1, Eastend, SK, Canada & Barley field & 2000 \\
Thl-24 to 27 & Site 3, Eastend, SK, Canada & Road allowance & 2000 \\
Thl-28 & Site 4, Eastend, SK, Canada & Barley field & 2000
\end{tabular}

(b) Reference strains compared in the study

\begin{tabular}{|llll|}
\hline Strains & Group/sub-group/species & Host and country of origin & Source (year collected) \\
\hline IBCN 2 & A, 'aggressive' & Brassica napus, Germany & H.-H. Hoppe (1992) \\
IBCN 26 & NA1, 'brassicae' & B. napus, Poland & Z. Karolewski (1991) \\
IBCN 30 & NA-Aus, 'australensis' & B. napus, Australia & B.J. Howlett (1991) \\
IBCN 64 & 'Thlaspii' & Thlaspi arvense, SK, Canada & G. Séguin-Swartz (1993) \\
IBCN 82 & 'Sisymbrii' & B. juncea, SK, Canada & G. Séguin-Swartz (1993) \\
IBCN 83 & 'Erysimii' & Erysimum sp., SK, Canada & G. Séguin-Swartz (1993) \\
IBCN 84 & 'Lepidii' & Lepidium sp., SK, Canada & G. Séguin-Swartz (1993) \\
IBCN 91 & NA3 & B. oleracea, USA & P.H. Williams (?) \\
IBCN 92 & NA2, 'canadensis' & B. rapa, Canada & P.H. Williams (?) \\
IBCN 65 & L. biglobosa 'Thlaspi' & T. arvense, SK,Canada & Mendes-Pereira et al. 2003 \\
& & & $(?)$ \\
O6VTJ154 & L. biglobosa & B. juncea, Australia & Van de Wouw et al. 2008 (?) \\
UK5 & L. biglobosa, brassicae & B. napus, UK & Lui et al. 2006 (?) \\
UK7 & L. maculans, brassicae & B. napus, UK & Lui et al. 2006 (?) \\
\hline
\end{tabular}

*Agriculture and Agri-Food Canada, ${ }^{* *}$ SK: Saskatchewan, Canada

\section{Phenotypic and biochemical characterization}

\section{Mycelial growth of isolates:}

Mycelial growth rates of the 'Thl' isolates were compared to those of reference strains IBCN 2 (A group) and IBCN 26 (NA1, brassicae sub-group) on V8-juice agar (V8A) and malt extract agar (MEA) [16]. Agar disks (4 mm diameter) bearing mycelium excised from the edge of 14-day-old cultures were placed at the centre of 9-cm diameter Petri plates. For each growth medium, there were three replicate plates per isolate and the plates were incubated at $20^{\circ} \mathrm{C}$ in the dark. Average daily growth rates were calculated for each isolate for the period of logarithmic growth.

\section{Production of pigments and sirodesmins:}

'Thl' isolates and strains IBCN 2 and IBCN 26 were inoculated in Czapek-Dox broth [16] amended with $2 \%$ yeast extract and $2 \%$ peptone and grown at $20^{\circ} \mathrm{C}$ in the dark on an orbital shaker $(100 \mathrm{rpm})$. After 28 days, the cultures were filtered through Buchner funnels fitted with Whatman filter paper no. 595 into test tubes and filtrate colour was assessed visually. The fungal ability to produce sirodesmins in nutrient broth was determined by thin layer chromatography [17].

\section{Pathogenicity tests on Canola plants}

Oilseed rape cultivar 'Lirabon' (Deutsche Saatveredelung, Lippstadt, Germany) was used in the pathogenicity tests because it is susceptible to P. lingam [18]. The pathogenicity test was performed as two plant growth stages.

\section{Cotyledon assay:}

Seedlings were grown in a growth chamber at $22^{\circ} \mathrm{C}$ with a $16 \mathrm{~h}$ photoperiod and 65 to $75 \%$ relative humidity. Sevenday-old seedlings were transplanted to multi-cell trays containing a mixture of peat moss, compost and sand $(1: 1: 0.1, \mathrm{v} / \mathrm{v})$ one day before inoculation. Both lobes of each cotyledon were punctured with an entomological needle and inoculated with a $10 \mu \mathrm{L}$ droplet of spore suspension $\left(10^{7}\right.$ pycnidiospores $/ \mathrm{mL}$ ). Seventeen plantlets were inoculated per isolate. Disease severity was assessed 14 days postinoculation (dpi) using a 0 to 6 rating scale [19]; each lesion was scored and mean disease severity was calculated for each isolate.

\section{Adult plant assay:}

Plants were grown in $13 \times 13 \mathrm{~cm}$ pots in a greenhouse at $24^{\circ} \mathrm{C}$ with a $16 \mathrm{~h}$ photoperiod. At the 3 to 4 true leaf stage, the axil of the first true leaf was wounded with a sterile entomological needle and inoculated with a mycelium plug ( $2 \mathrm{~mm}$ diam) excised from a 10-day-old oatmeal agar culture [16]. Inoculated plants were covered with polyethylene film for $72 \mathrm{~h}$. Each isolate was tested on 17 plants. Disease severity was assessed using a modification of the method of [20]. Lesion length (L) (scale $=0$ : no infection, 1: 1-4 mm, 2: 5-8 mm, 3: 9-12 mm, 4: 13-16 mm, 5: 17-20 mm, 6: 21$24 \mathrm{~mm}, 7: 25-28 \mathrm{~mm}, 8: 29-32 \mathrm{~mm}, 9:>32 \mathrm{~mm}$ ), extent of stem girdling $(\mathrm{G})$ and lesion depth (D) (scale $=0$ : no infection, 1: $>0-11 \%, 2: 12-22 \%, 3: 23-33 \%, 4: 34-44 \%, 5$ : $45-55 \%, 6: 56-66 \%, 7: 67-77 \%, 8: 78-88 \%, 9:>88 \%)$ were assessed at 49 dpi.

The volume of diseased tissue (VDT) was calculated for each combination of plant and isolate according to the following formula: $\mathrm{VDT}=\left(1-\mathrm{HR}^{2}\right) \times \mathrm{G} / 9 \times \mathrm{L}$, where $\mathrm{HR}=$ $1-\mathrm{D} / 9$.

The mean VDT was then calculated for each isolate.

\section{Analyses of genetic diversity of $P$. lingam isolates}

\section{Extraction of fungal DNA:}

IBCN reference and 'Thl' isolates were grown in CzapekDox broth supplemented with $0.1 \%$ peptone. Three-week-old cultures were filtered using Buchner funnels fitted with 90 $\mathrm{mm}$ filter discs and the mycelium was lyophilized. Total genomic DNA was extracted using Qiagen's DNeasy Plant Mini Kit according to the manufacturer's instructions. The

\section{Volume 5 Issue 8, August 2016}




\section{International Journal of Science and Research (IJSR) \\ ISSN (Online): 2319-7064 \\ Index Copernicus Value (2013): 6.14 | Impact Factor (2015): 6.391}

following three genomic loci were studied for defining the genetic diversity of the $P$. lingam isolates.

Variable Number of Tandem Repeats (VNTR) fingerprinting:

PCR reactions of $25 \mu \mathrm{L}$ final volume containing $25 \mathrm{ng}$ template DNA, $0.2 \mathrm{mM}$ each dNTP, $1.5 \mathrm{mM} \mathrm{MgCl}_{2}, 1 \mu \mathrm{M}$ primer 5'-ggtggcggctct-3' [21], 1.25 units Taq DNA polymerase and $1 \mathrm{X}$ concentrated reaction buffer were run using a T-Gradient thermocycler (Biometra $\mathrm{GmbH}$, Göttingen, Germany). The thermocycler was set up for 30 cycles $\left(4 \mathrm{~min}\right.$ at $94^{\circ} \mathrm{C}, 1 \mathrm{~min}$ at $57^{\circ} \mathrm{C}$ and $3 \mathrm{~min}$ at $72^{\circ} \mathrm{C}$ ). Amplified fragments were separated on $1.5 \%$ agarose gels and examined the banding patterns with the Bio-Rad Video Gel Documentation System and images were taken.

\section{Enterobacterial Repetitive Intergenic Consensus (ERIC) fingerprinting:}

The PCR reaction setup and concentration of components were identical to that used for VNTR-PCR. Primers ERIC1R $\left(5^{\prime}\right.$-atgtaagctcctggggattacc-3') and ERIC2 (5'aagtaagtgactggggtgagcg-3') [22, 23] were used. DNA amplification was performed for 36 cycles $\left(2 \mathrm{~min}\right.$ at $95^{\circ} \mathrm{C}, 1$ $\min$ at $52^{\circ} \mathrm{C}$ and $3 \mathrm{~min}$ at $65^{\circ} \mathrm{C}$ ). Amplified fragments were separated on 5 to $10 \%$ polyacrylamide gradient gels and stained and documented as for VNTP-PCR.

\section{ITS-rRNA gene sequence comparisons}

The ITS region of the rRNA of the 'Thl' and reference isolates was amplified using primers ITS4 (5'tcctccgettattgatatgc- $\left.3^{\prime}\right)$ and ITS5 (5'ggaagtaaaagtcgtaacaagg-3') [24]. The PCR reaction components and concentration were similar to those used for VNTR- and ERIC-PCR, except that Vent- polymerase was used instead of Taq-polymerase. Amplification was performed for 90 cycles $\left(3 \mathrm{~min}\right.$ at $94^{\circ} \mathrm{C}, 1 \mathrm{~min}$ at $54^{\circ} \mathrm{C}$ and 1 min at $72^{\circ} \mathrm{C}$ ). Aliquot three microliters of amplicon was run on $0.8 \%$ agarose gel and visualized the size polymorphisms of ITS-rRNA fragments of $P$. lingam isolates. The PCR products were purified using a DNA Clean and Concentrator-5 kit (Zymo Research Corporation), blunt ended and ligated into linearized pMiniT ${ }^{\mathrm{TM}}$ Vector using a NEB ${ }^{\circledR}$ PCR cloning kit and protocols. The inserted fragments were PCR amplified using the plasmid embedded primers L30350F (acctgccaaccaaagcgagaac) and L71-1R (tcagggttattgtctcatgagcg) and sequenced. The sequence similarity was searched using NCBI database. Reference strains that were not sequenced in the study were: $L$. biglobosa brassicae UK5 (Q133890), L. maculans brassicae UK7 (DQ133891), L. biglobosa China (KJ574214), L. biglobosa erysimii (AJ550872) and L. biglobosa Thlaspii (AJ550891). Phylogenetic diversity among and between 'Thl' and IBCN reference strains was demonstrated by constructing a dendrogram based on Unweighted Pair Group Method with Arithmetic mean (UPGMA) algorithm using MEGA 6.0 software [25].

\section{Results and Discussion}

\section{Morphological and biochemical characteristics of $\boldsymbol{P}$. lingam isolates}

The exponential growth on MEA of most 'Thl' isolates appeared to be similar to non-aggressive reference strain IBCN 26 (L. biglobosa) (4.9 mm/day) (Figure 1a). Thl-21, Thl-22 and Thl-27 grew slightly faster $(6.6-7.1 \mathrm{~mm} /$ day) than IBCN 26. In contrast, Thl-11, Thl-18, Thl-19 and Thl24 had significantly $(p<0.05)$ slower growth rates similar to aggressive reference strain IBCN 2 (2.3 mm/day). Similarly, most 'Thl' isolates had growth rates on V8A similar to that of IBCN $26(9.0 \mathrm{~mm} /$ day $)$ and greater than $(p \leq 0.05)$ that of IBCN 2 (6.0 mm/day) (Figure 1b). Thl-18 had a similar growth rate to IBCN 2 and Thl-11 was intermediate (7.3 $\mathrm{mm}$ /day) between IBCN 2 and IBCN 26. Isolates of $P$. lingam non-aggressive on brassica crops appeared to be generally faster growing than aggressive isolates on culture media [12], suggesting that the 'Thl' isolates would be nonaggressive to oilseed rape and related crops.

The culture filtrates of non-aggressive isolates typically contain coloured pigments in liquid culture, e.g., phomaligin a [26], while culture filtrates of aggressive isolates are typically colourless [12]. Non-aggressive isolates are unable to produce the host nonspecific sirodesmin toxins that are characteristic of aggressive isolates and may be involved in pathogenicity $[12,27]$. The culture filtrates of all 'Thl' isolates and the non-pathogenic reference strain (IBCN 26) were coloured and did not contain sirodesmins (Figure 2 and $3)$. In contrast, the pathogenic reference strain (IBCN 2) produced colorless pigments and synthesized sirodesmins (Figure 2). This suggests that the 'Thl' isolates were nonaggressive to canola.
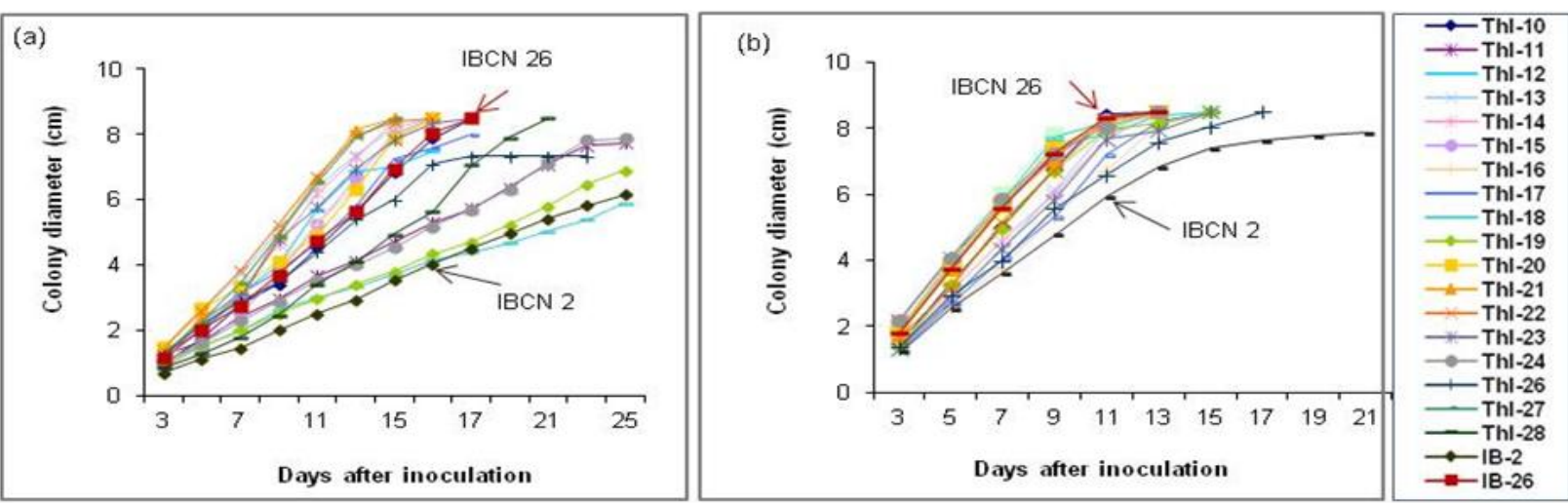

Figure 1: Colony growth of the 'Thl' isolates compared to $P$. lingam reference strains from IBCN reference collections. (a) and (b) show the fungal growth patterns on malt extract and V8 agar media, respectively. IBCN 2 and IBCN 26 denotes aggressive and non-aggressive reference strains. 


\section{International Journal of Science and Research (IJSR) \\ ISSN (Online): 2319-7064}

Index Copernicus Value (2013): 6.14 | Impact Factor (2015): 6.391

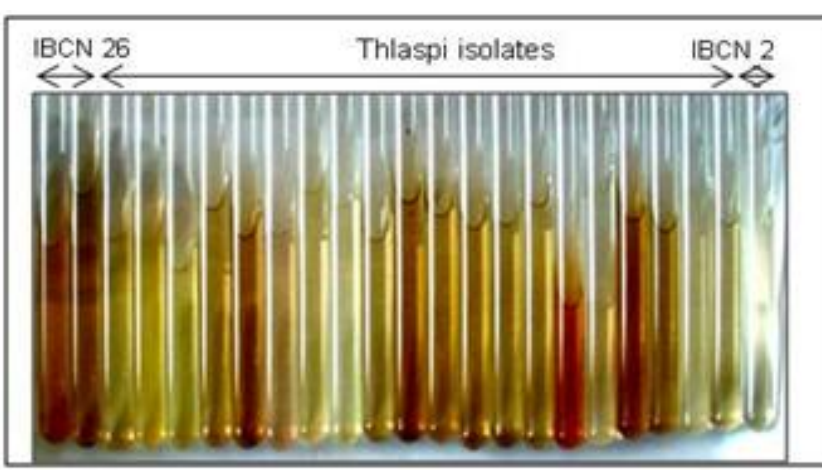

Figure 2: Production of coloured pigments by $P$. lingam isolates. IBCN 2 and IBCN 26 denote aggressive and nonaggressive reference strains, respectively.

\section{Pathogenecity of $\boldsymbol{P}$. lingam isolates}

The aggressiveness of the 'Thl' isolates was assessed on cotyledons and stem tissue of older plants since resistance of oilseed rape at the cotyledon stage is not always correlated with adult plant resistance [28] and genes regulating these traits are different [29]. Lesions on cotyledons inoculated with IBCN 2 were characterized by collapsed grey-green tissue, diffused margins, and numerous pycnidia at $14 \mathrm{dpi}$ (Figure $4 \mathrm{a}$ ); disease severity was $>4.0$ using the 0 to 6 scale. Plants inoculated with the non-aggressive IBCN reference strains and the 'Thl' isolates showed a hypersensitive response, a limited dark lesion with no pycnidia or no symptoms (Figure 4b); disease severity ranged from 0 to 1.5 . Isolate IBCN 2 caused significant internal damage to stem tissue (Figure 4c); the other IBCN strains and the 'Thl' isolates caused small, superficial stem lesions (Figure 4d). The disease severity of IBCN 2 and 'Thl' isolates were expressed as VDT values and determined to be VDT $>2.4$ and 0.1 to 1.0 , respectively $(p<0.01$ ) (Figure 5). The pathogenicity tests confirmed that the 'Thl' isolates were not aggressive on susceptible B. napus cultivar 'Lirabon'.

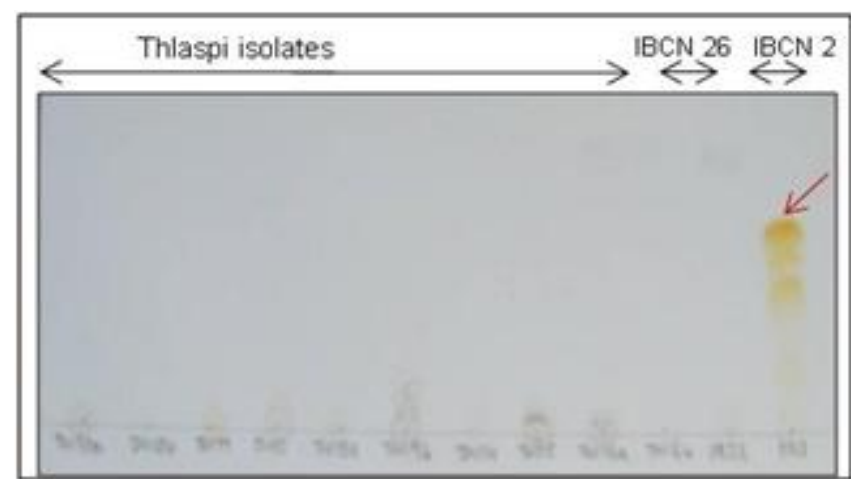

Figure 3: In vitro sirodesmins production by the $P$. lingam isolates. IBCN 2 and IBCN 26 indicate aggressive and nonaggressive reference strains, respectively.

\section{Genetic diversity of $\boldsymbol{P}$. lingam isolates}

Preliminary genetic structure and variability of $P$. lingam isolates from different host plant species were studied using PCR-based ERIC and VNTR fingerprinting techniques. ERIC and VNTRs are located in non-coding regions and are distributed throughout many eukaryotic genomes with a high heterogeneity. These regions are useful to characterize microbial populations at the genus, species and strain level [21, 30, 31]. VNTR fingerprints exhibited considerable polymorphisms among the IBCN reference isolates analyzed (Figure 4, lanes 2-10) (Figure 6). The band profiles clearly visualized diversity between the reference strains and the 'Thl' isolates, including the 'Thl' reference strain (IBCN 64). The banding patterns of the 'Thl' isolates (Figure 6, lanes 12-29), showing 7 to 14 bands ranging from $350 \mathrm{bp}$ to $3 \mathrm{~kb}$, were visibly distinguishable from those of the IBCN strains. The fingerprinting technique detected at least seven different
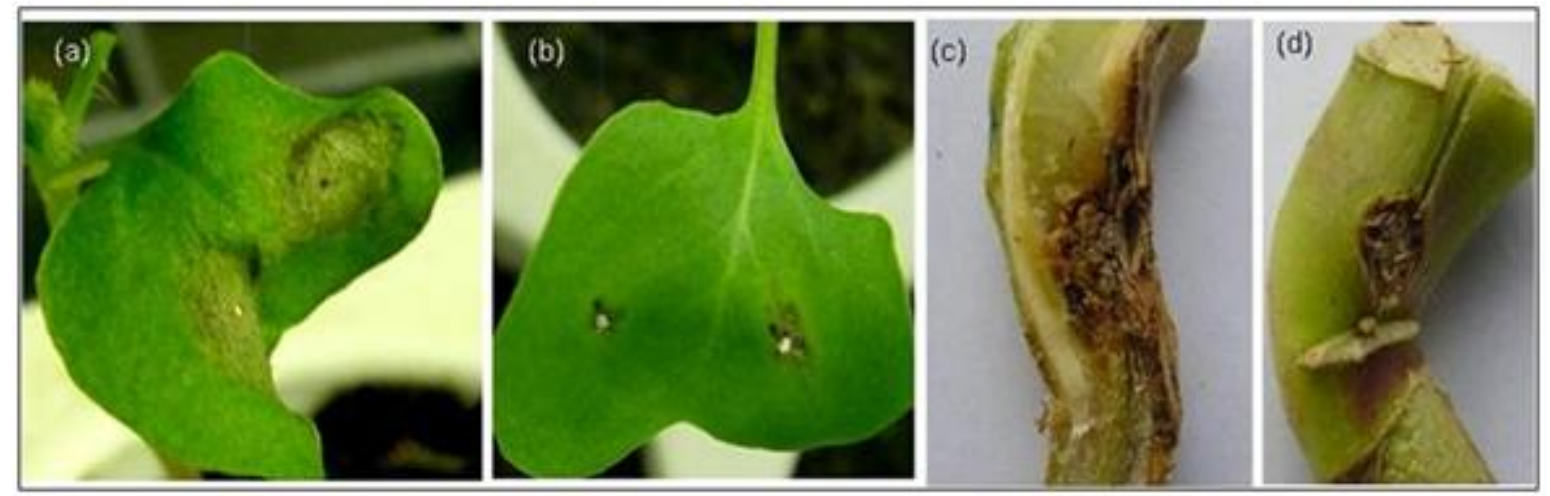

Figure 4: Response of cotyledons and stems of B. napus cultivar Lirabon to Phoma lingam isolates. (a) Cotyledon tissue collapse caused by the virulent reference strain IBCN 2, and (b) hypersensitive-like symptoms caused by a 'Thl' isolate. (c) Strain IBCN 2 shows canker on stem bases. (d) Small superficial canker lesion at stem bases caused by a 'Thl' isolate. 


\section{International Journal of Science and Research (IJSR) \\ ISSN (Online): 2319-7064}

Index Copernicus Value (2013): 6.14 | Impact Factor (2015): 6.391

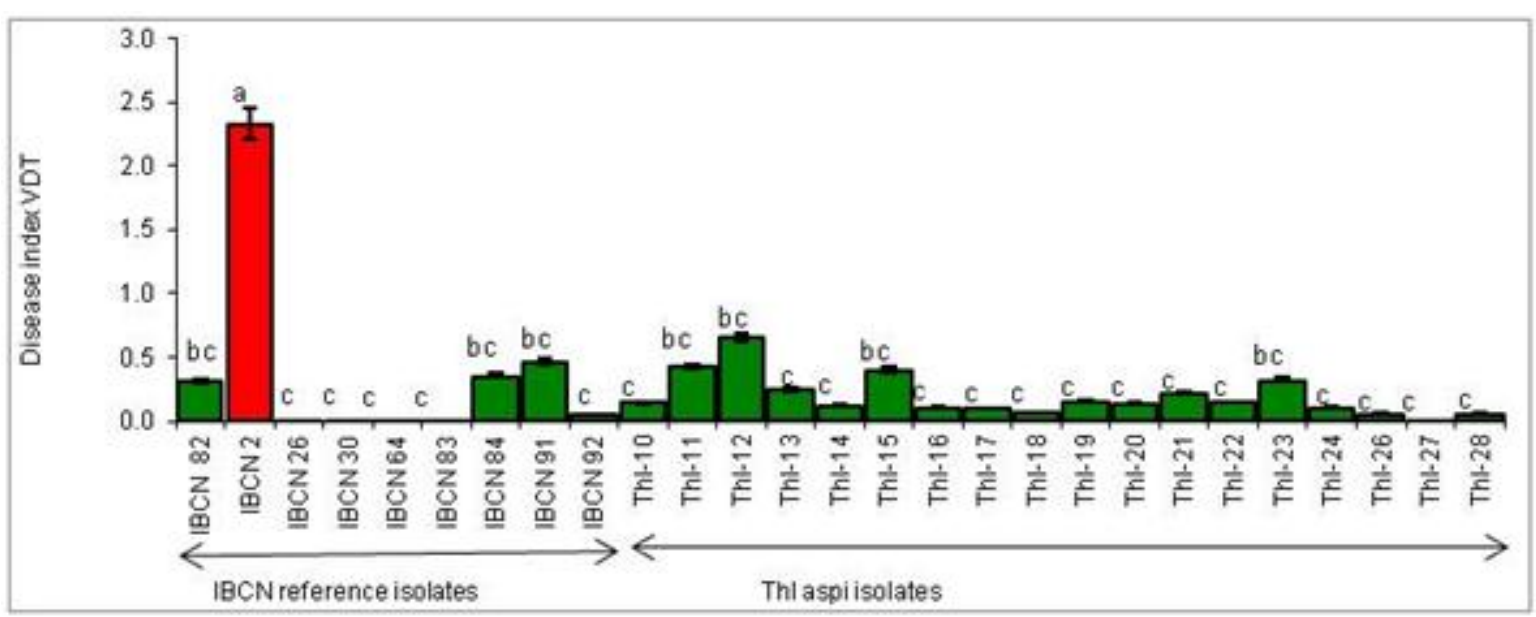

Figure 5. Disease severity on stem bases of B. napus cultivar 'Lirabon' 49 days post-inoculation with Phoma lingam isolates. Bars followed by different letters are statistically different from each other $(p<0.05)$. IBCN 2 and IBCN 26, aggressive and less/non-aggressive reference strains, respectively

band profiles among the 'Thl' isolates. Isolates Thl-10, -11, $12,-13-18$ and -24 generated separate band profiles comprised of $7,8,14,14,9$ and 8 bands, respectively. The largest genotype, comprised of 13 isolates (Thl-14 to 17,19 to 23 and 27 to 28 ), showed a profile of 14 bands. Based on ERIC band profile, isolate Thl-26 could be assigned to the last genotype. Similar to VNTR, the ERIC method revealed obvious variability in band profiles among 'Thl' isolates and between reference strains (data not shown). Analysis of ITSrRNA gene sequences discriminated 'Thl' isolates from the IBCN reference strains, including a previously characterized 'Thl' strain (IBCN 65). The diversity could be visualized by different sizes of ITS-rRNA gene fragments of the isolates on an agarose gel (data not shown). The UPGMA dendrogram created from ITS-rRNA sequences revealed a highly heterogeneous 'Thl' population (Figure 7). The 'Thl' population evaluated in this study could be distributed into eight clusters, namely cluster - 1, 2, 3, 6, 7, 8, 9 and 10 .

Of the 'Thl' isolates, 10 showed relationships to eight nonaggressive reference strains belonging to L. biglobosa. This finding is supported by Balesdent and co-authors [32], who suggested the occurrence of highly heterogeneous $P$. lingam in western Canada. One isolate (Thl-12) showed a close relationship with a previously characterized 'Thl' isolate (ICBN 65) (cluster 3) that was collected from an area where the tested 'Thl' isolates were collected a few years later [33]. This suggests that significant temporal restructuring of $P$. lingam populations can occur on T. arvense. In regard to crop fields, the 'Thl' population from canola fields (Thl-10 to 13) and road allowance (Thl-24 to 27) appeared to be highly heterogeneous as compared to the population from barley fields.

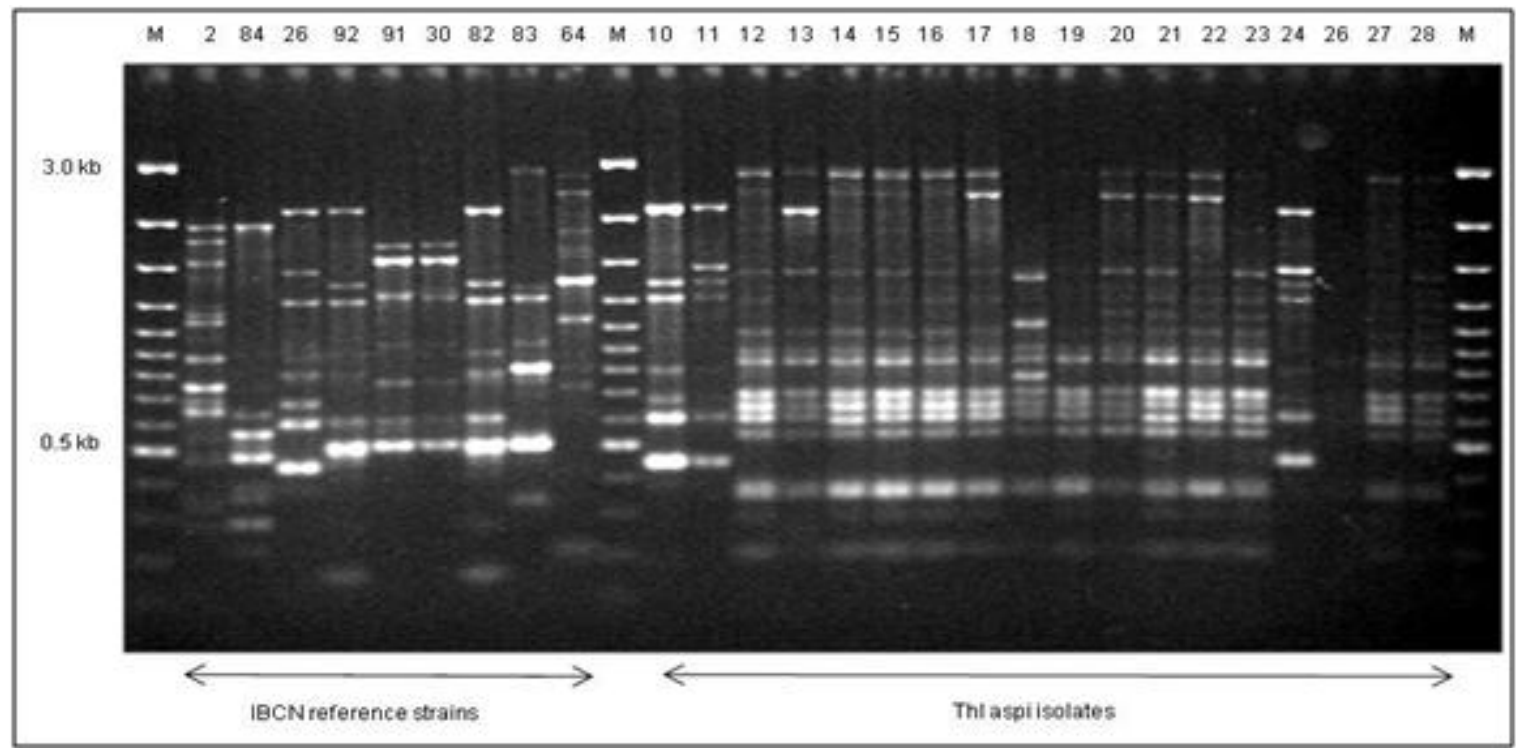

Figure 6: Band profiles of the Variable Number of Tandem Repeats (VNTR) locus generated from Phoma lingam isolates on $1.5 \%$ agarose gel. M, DNA marker. 
International Journal of Science and Research (IJSR)

ISSN (Online): 2319-7064

Index Copernicus Value (2013): 6.14 | Impact Factor (2015): 6.391

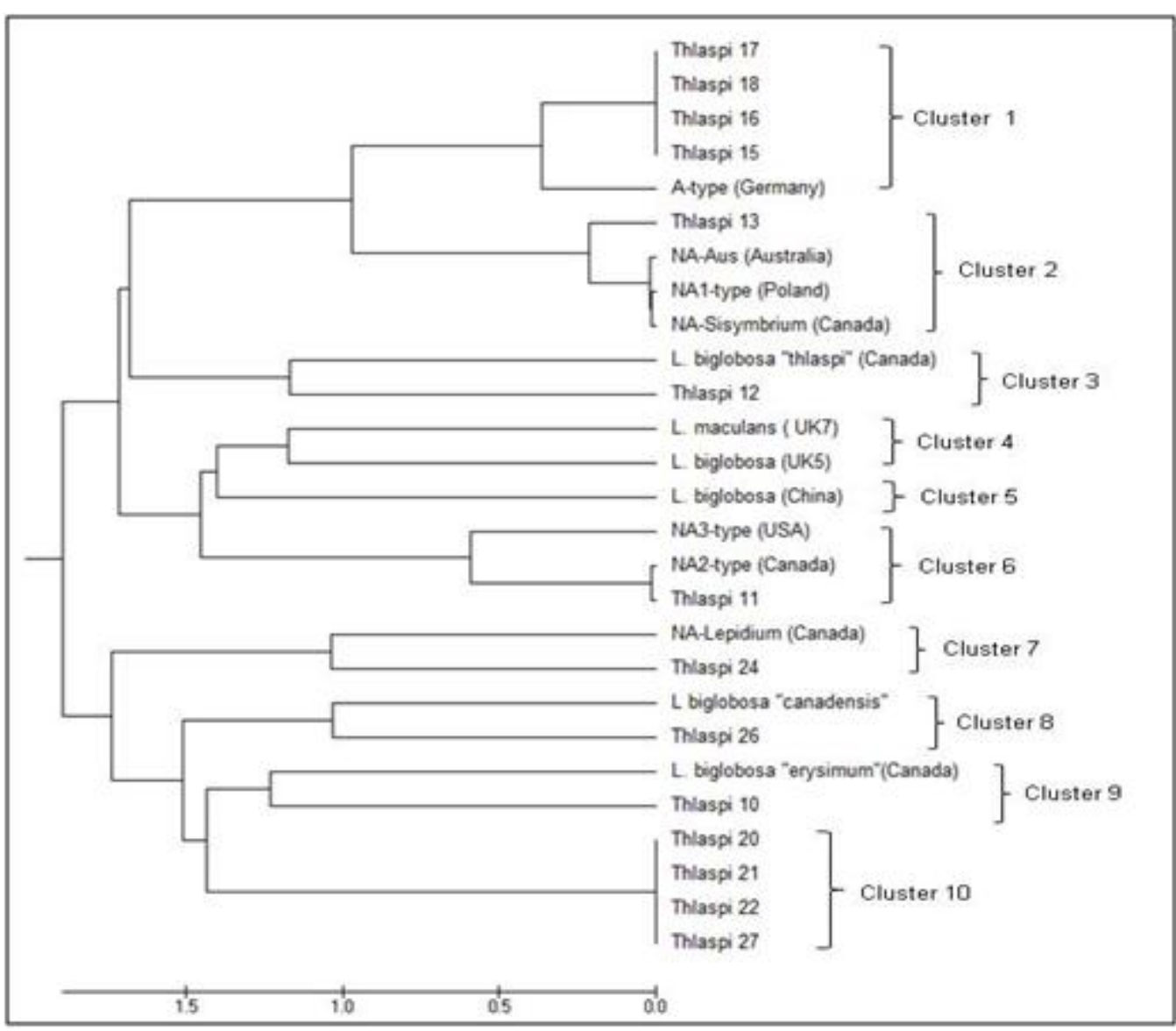

Figure 7: UPGMA distance tree shows genetic diversity of 'Thl' Phoma lingam isolates in comparison with reference strains. The dendrogram was created using ITS-rRNA gene sequences by MEGA6 software.

Populations from the two crop fields were found to be significantly diverse from each other. The 'Thl' isolates from barley fields could be divided into two distinct genotypes (cluster - 1 and 10). Four isolates (Thl-20, 21, 22 and 27) (cluster - 10) appeared to be distinct from all other 'Thl' and reference strains. None of the 'Thl' isolates were found to be related to a pathogenic L. maculans strain collected in UK, and two L. biglobosa strains from the UK and China [15]. Importantly, a set of four isolates from barley fields (Thl-15, 16, 17 and 18) showed a close relationship with an aggressive strain (IBCN 2) originating from B. napus in Germany (cluster - 1). This may be of concern if 'Thl' $P$. lingam population biology changes from non-pathogenic to pathogenic during their adaptation to global environmental changes [34]. The shift of non-aggressive L. biglobosa populations to an aggressive state, resulting in crop losses on different continents, has been reported $[13,35]$.

\section{Conclusion}

The morphological and biochemical characteristics, pathogenicity on B. napus cv. 'Lirabon' (susceptible to blackleg disease) and molecular analyses revealed that the $P$. lingam that infects $T$. arvense in Saskatchewan, Canada comprised of multiple genotypes and belonged to non/less pathogenic sexual state of $P$. lingam, namely L. biglobosa. Molecular fingerprinting and phylogenetic analysis of ITS sequences suggest the occurrence of significant genetic restructuring of the 'Thl' population, possibly due to the adverse effects of climate change and sexual recombination among 'Thl' and other strains co-existing in T. arvense plants [36]. The dynamic nature of 'Thl' P. lingam populations implies further challenges in the development of disease management strategies, specifically, screening germplasms for introduction of varieties resistant to L. biglobosa. Although the life cycles of sexual states of the pathogen are similar and both may exist in a similar agroecological niche [35], isolates of L. maculans appear to be genetically stable and show gene-for-gene interactions with all their Brassica hosts (B. napus, B. rapa, B. oleracea, $B$. juncea, etc.). In contrast, such specialized interactions have not been found with isolates of L. biglobosa [13]. The pathogenicity-related genes of $P$. lingam vary significantly with host plant, and to new environmental conditions [34, 37]. Analysis of isolates at regular intervals on locally grown host plant cultivars is needed to understand their potential migration from a non-aggressive to an aggressive state.

\section{Acknowledgements}

The authors gratefully acknowledge the German Academic Exchange Service (DAAD) for providing financial support to Rafiq Ahad for his M.Sc. thesis research.

\section{References}

[1] West J.S., P.D. Kharbanda, M.J. Barbetti, Bruce DL Fitt (2001) Epidemiology and management of Leptosphaeria maculans (phoma stem canker) on oilseed rape in Australia, Canada and Europe. Plant Pathology, 50:10-27 


\section{International Journal of Science and Research (IJSR) \\ ISSN (Online): 2319-7064}

Index Copernicus Value (2013): 6.14 | Impact Factor (2015): 6.391

[2] Howlett B.J. (2004) Current knowledge of the Brassica napus-Leptosphaeria maculans interaction: a review. Canadian Journal of Plant Pathology, 24:245-252

[3] Purwantara A., J.M. Barrins, A.J. Cozijnsen, P.K. Ades, B.J. Howlett (2000) Genetic diversity of isolates of the Leptosphaeria maculans species complex from Australia, Europe and North America using amplified fragment length polymorphism analysis. Mycological Research, 104:772-781

[4] Dilmaghani A., M.H. Balesdent, J.P. Didier, C. Wu, J. Davey, M.J. Barbetti, et al. ( 2009) The Leptosphaeria maculans-Leptosphaeria biglobosa species complex in the American continent. Plant Pathology, 58:10441058

[5] Williams R.H., B.D. Fitt (1999) Differentiating A and B groups of Leptosphaeria maculans, causal agent of stem canker (blackleg) of oilseed rape. Plant Pathology, 48:161-175

[6] West J.S., M.H. Balesdent et al. (2002) Colonization of winter oilseed rape tissues by $\mathrm{A}^{-} \operatorname{Tox}^{+}$and $\mathrm{B} / \mathrm{Tox}^{0}$ Leptosphaeria maculans (phoma stem canker) in France and England. Plant Pathology, 51:311-321

[7] Shoemaker R.A., H. Brun (2001) The teleomorph of the weakly aggressive segregate of Leptosphaeria maculans. Canadian Journal of Botany, 79:412-419

[8] Voigt K., A.J. Cozijnsen, J. Kroymann, S. Poggeler, B.J. Howlett (2005) Phylogenetic relationships between members of the crucifer pathogenic Leptosphaeria maculans species complex as shown by mating type (MAT1-2), actin and tubulin sequences. Molecular Phylogenetics and Evolution, 37:541-557

[9] Fitt B.D.L., B.C. Hu, Z.Q. Li et al. (2008) Strategies to prevent spread of Leptosphaeria maculans (phoma stem canker) onto oilseed rape crops in China; costs and benefits. Plant Patholology, 57: 652--664

[10] Koopmann B., E. Führer-Ithurrat, B. Volke, J. Sock, H.H. Hoppe (2003) Strain variation in Phoma lingam, the incitant of blackleg of oilseed rape. Proceedings of the 11th International Rapeseed Congress; July 6-10; Copenhagen. Denmark: Royal Veterinary and Agricultural University

[11] Mendes-Pereira E., M.H. Balesdent, H. Brun, T. Rouxel (2003) Molecular phylogeny of the Leptosphaeria maculans-L. biglobosa species complex. Mycological Research, 107:1287-1304

[12] Voigt K., M. Jedryczka, J. Wöstemeyer (2001) Strain typing of Polish Leptosphaeria maculans isolates supports at the genomic level the multi-species concept of aggressive and non-aggressive strains. Microbiolgical Research, 156:169-177

[13] Vincenot L., et al. (2008) Occurrence of a new subclade of Leptosphaeria biglobosa in Western Australia. Phytopathology, 98:321-329

[14] Fitt B.D.L., H. Brun, M.J. Barbetti, S.R. Rimmer (2006) World-wide importance of phoma stem canker (Leptosphaeria maculans and L. biglobosa) on oilseed rape (Brassica napus). European Journal of Plant Pathology, 114:3-15

[15] Liu Z., A.O. Latunde-Dada, A.M. Hall, B.D.L. Fitt (2014) Phoma stem canker disease on oilseed rape (Brassica napus) in China is caused by Leptosphaeria biglobosa 'brassicae'. European Journal of Plant Pathology, 140:841-857
[16] Islam M.R. (2004) Characterization of Phoma lingam isolates recovered from Canadian accessions of Thlaspi arvense. M.Sc. thesis, Georg-August-University of Göttingen, Göttingen, Germany

[17] Koch E., M.A. Badawy, H.H. Hoppe (1989) Differences between aggressive and non-aggressive single spore lines of Leptosphaeria maculans in cultural characteristics and phytotoxin production. J Phytopathology, 124:52-62

[18] Kuswinanti T., B. Koopmann, H.H. Hoppe (1999) Virulence pattern of aggressive isolates of Leptosphaeria maculans on an extended set of Brassica differentials. Z Pflanzenkrank Pflanzensch, 106:12-20

[19] Volke B. (2000) Leptosphaeria maculans, der Erreger Wurzelhals-und Stengelfäule an Raps: Verbreitung verschiedener Pathogenitätsgruppen in Europa, Quantifizierung des Befalls und Schadwirkung im Freiland [desertation]. Göttingen, Germany: GeorgAugust-University of Göttingen

[20] Kutcher H.R., C.G.J. van den Berg, S.R. Rimmer (1993) Variation in pathogenicity of Leptosphaeria maculans on Brassica spp. based on cotyledon and stem reactions. Canadian Journal of Plant Pathology, $15: 253-258$

[21] Heath D.D., G.K. Iwama, R.H. Devlin (1993) PCR primed with VNTR core sequences yields species specific patterns and hypervariable probes. Nucleic Acids Research, 21:5782-5785

[22] Gillings M., M. Holley (1997) Amplification of anonymous DNA fragments using pairs of long primers generates reproducible DNA fingerprints that are sensitive to genetic variation. Electrophoresis, 18:1512-1518

[23] Weingart H., B. Völksch (1997) Genetic fingerprinting of Pseudomonas syringae pathovars using ERIC-, REP-, and IS50-PCR. Journal of Phytopathology, 145:339-345

[24] White T.J., T. Bruns, S. Lec, J. Taylor (1990) PCR Protocols: Amplification and direct sequencing of fungal ribosomal RNA genes for phylogenetics. Academic Press Inc: New York

[25] Tamura K., G. Stecher, D. Peterson, A. Filipski, S. Kumar (2013) MEGA6: molecular evolutionary genetics analysis version 6.0. Mol biol evolution, 30:2725-2729

[26] Pedras M.S.C., J.L. Taylor, V.M. Morales (1995) Phomaligin a and other yellow pigments in Phoma lingam and $P$. wasabiae. Phytochemistry, 38:12151222

[27] Badawy H.M.A., H.H. Hoppe (1989) Production of phytotoxic sirodesmins by aggressive strains of $L$. maculans differing in interactions with oil seed rape genotypes. J Phytopathology, 127:146-157

[28] Hammond K.E., B.G. Lewis (1987) Variations in stem infections caused by aggressive and non-aggressive isolates of L. maculans on Brassica napus var. oleifera. Plant Pathology, 36:53-65

[29] Zhu B., S.R. Rimmer (2003) Inheritance of resistance to Leptosphaeria maculans in two accessions of Brassica napus. Canadian Journal of Plant Pathology, 25:98-103

[30] Edel V., C. Steinberg, I. Avelange, G. Laguerre, C. Alabouvette (1995) Comparison of three molecular 


\section{International Journal of Science and Research (IJSR) \\ ISSN (Online): 2319-7064}

Index Copernicus Value (2013): 6.14 | Impact Factor (2015): 6.391

methods for the characterization of Fusarium oxysporum strains. Phytopathology, 85:579-585

[31] Jedryczka M., T. Rouxel, M.H. Balesdent, E. MendesPereira, J. Bertrandy (1997) Molecular characterization of Polish Phoma lingam isolates. Cereal Research Communications, 25:279-283

[32] Balesdent M.H., M.j. Barbetti, H. Li, K. Sivasithamparam, L. Gout, T. Rouxel (2005) Analysis of Leptosphaeria maculans race structure in a worldwide collection of isolates. Phytopathology, 95:1061-1071

[33] Balesdent M.H., M. Jedryczka, L. Jain, E. MendesPereira, J. Bertrandy, T. Rouxel (1998) Conidia as a substrate for internal transcribed spacer-based PCR identification of members of the Leptosphaeria maculans species complex. Phytopathology, 88:12101217

[34] Barbetti M.J., S.S. Banga, P.A. Salisbury (2012) Challenges for crop production and management from pathogen biodiversity and diseases under current and future climate scenarios-case study with oilseed Brassicas. Field Crops Research, 127:225-240

[35] Fitt B.D.L., Y.J. Huang, F. van den Bosch, J.S. West (2006) Coexistence of related pathogen species on arable crops in space and time. Annual Review of Phytopathology, 44 :163-82

[36] Petrie G.A., G. Séguin-Swartz, R.K. Gugel (1995) Latent infection of Brassicaceae in the field by Leptosphaeria maculans (blackleg). Canadian Journal of Plant Pathology, 17:75-81

[37] Marcroft S.J., A.P. van de Wouw, P.A. Salisbury, T.D. Potter, B.J. Howlett (2012) Effect of rotation of canola (Brassica napus) cultivars with different complements of blackleg resistance genes on disease severity. Plant Pathology, 61:934-944 